\title{
COMPUTER PROGRAM FOR PREDICTING EMISSION UNIFORMITY OF ODD-SHAPED SUBUNITS IN DRIP IRRIGATION SYSTEM
}

\author{
A. Mahrous ${ }^{1}$, M. Hanafy ${ }^{2}$, G. A. Bakeer ${ }^{2}$ and A. S. Bazaraa ${ }^{3}$
}

\section{ABSTRACT}

Computer program was made to predict the emission uniformity in oddshaped irrigation subunits. The computer program of Odd-shaped Subunits Designer [OSSD] contains three modules; first dealing with emitter characteristics, second dealing with subunit geometry and third dealing with subunit design. The results of this work indicated that the predicted values of the emission uniformity in rectangular, trapezoidal and triangular irrigation subunits of equal area were in good agreement with field measurement.

\section{INTRODUCTION}


odern irrigation systems are better methods from both engineering and agriculture view points to produce varity of crops such as citrus, banana and vegetables. System design plays a main role to maximize the emission uniformity, the one of criteria that affects on the design quality, in modern irrigation systems, but the emission uniformity depends on field measurements as minimum emitter discharge and average emitter discharge and there is no method to predict it before the system installation. Also, there are several odd-shaped land areas (triangular or trapezoidal) as parts between center pivots systems. These surfaces need a method to predict the emission uniformity and maximizing it. Most of the available theory and design procedures are set to handle plots of uniform even shapes. System design also reducing initial and running costs. The purpose of this research is to develop a computer model to make a detailed design for the pre-selected subunit shape and configurations to make the comparisons and final selection. In the last decade, the finite-element method has been applied to analyze hydraulics of drip irrigation submain units (Bralts and Segerlind 1985; Bralts et al. 1993; Kang and Nishiyama 1994; Kang et al. 1995).

(1) Assist. Prof., Ag. Eng. Dept., Faculty of Agriculture, Cairo University.

(2) Prof., Ag. Eng. Dept., Faculty of Agriculture, Cairo University.

(3) Prof. Hydraulic \& Irri. Dept., Faculty of Engineering, Cairo University. 
Kang et al. (1996) developed a method for design of drip irrigation submain units based on the required average emitter discharge and the required uniformity of water application by applying the finite element method. Sharaf (1991) developed a hydraulic design model for drip irrigation system. The model used in selecting the optimum entrance of the submain to the manifold was capable of dealing with complex undulating slopes with lateral of various lengths. Another model developed by Sharaf (1996) to find the optimum design of simple submain unit. The optimization based on eliminating the total annual cost at specific flow variation. Reddy et al. (2000) developed software (Drip$\mathrm{CAD}$ ) to solve sets of equation to determine economical pipe sizes based on emission uniformity and total annual cost. Gomes (1996) and Sosa (1996) developed a simulation program of irrigation pipeline system. Their algorithms include all variables that affect the cost of the piping system. Ismail et al. (2001) developed an interactive computer model called Micro-CAD to be used in design, planning and cost estimation of trickle systems. The Micro-CAD is supported by databases for the properties of the most common emitters, crops and land zones climate and soil properties. Awady and Ahmed (1996) developed a computer model to find the optimum planning of trickle irrigation networks. AbdelWahed (2002) developed software for estimating water requirements of some crops, scheduling, planning, designing and cost estimation of drip irrigation. Sharaf (2004) developed a simple design procedure for hydraulic analyses and uniformity evaluation and computer simulation model called Back Step Method to verify and evaluate the design procedure. This study indicated that the lateral length and the slopes have greater effect on subunit uniformity than manifold length and slope. Emitter discharge is considered to be a spatial variable, which overcomes the uniform emitter discharge assumption used in the methods presented by Keller and Bliesner (1990) and Wu and Gitlin (1975). Kang et al. (1996) developed a simplified method for designing drip irrigation laterals using the lateral flow rate equation.

\section{COMPUTER MODEL}

The objective of the computer program (Odd-shaped Subunits Designer [OSSD]) is to find out the distribution uniformity of different shapes of 
drip irrigation subunits. The design emission uniformity of the oddsubunit depends (Mahrous et al. 2004) on the manufacturer coefficient of variation, the emitter discharge and the number of emitters per plant, equation 1.

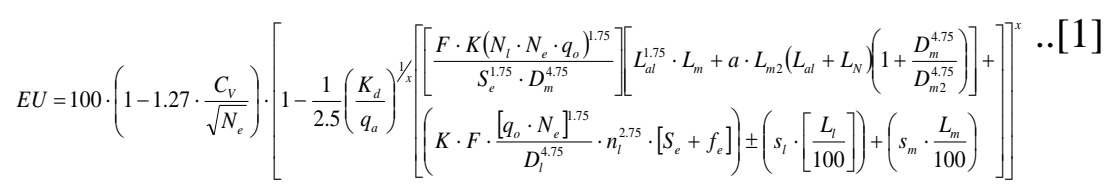

Where; EU is the design emission uniformity, $C_{v}$ is the manufacturer's coefficient of variation, $N_{e}$ is the number of emitters per plant, $x$ is the emitter exponent, $D_{l}$ is the inside diameter of the lateral, $D_{m}$ is the inside diameter of the manifold, $L_{m}$ is the lateral length, $K$ is conversion and Hazen Williams coefficient (789000), $K_{d}$ is the emitter constant, $S_{l}$ is the lateral slope, $S_{m}$ is the manifold slope, $L_{a l}$ is the average lateral length, $L_{m 2}$ is the second part length of manifold, which have $\mathrm{D}_{\mathrm{m} 2}, L_{N}$ is the last lateral length, $q_{a}$ is the average emitter discharge, $S_{f}$ is the shape factor, $F$ is the reduction factor, $S_{e}$ is the distance between outlets on the lateral, $S_{L}$ is the distance between lateral on the manifold, $N_{l}$ is the number of laterals on the manifold, $n_{l}$ is the number of outlets on the last lateral, $f_{e}$ is the emitter connection loss as an equivalent length, $\Delta S_{m}$ is the difference slope in the lateral, and $\Delta S_{l}$ is the difference slope in the lateral.

\section{Computer program for determination the design emission uniformity}

The computer program of Odd-shaped Subunits Designer [OSSD] was written using Delphi language (Object Pascal Language) version 6.0. To illustrating the general process for designing a drip irrigation system based on diverted design emission uniformity equation (1), the following procedures are emphasized in the paper:

\section{The main program}

The program has two facilities to input or select the data needed to predict the emission uniformity according to design criteria (fig. 1). The expertise user can input the needed data; otherwise permit the automatic selection by program in case of user has no experience. The program can be magnifying the emission uniformity by changing the manifold and lateral diameters. 

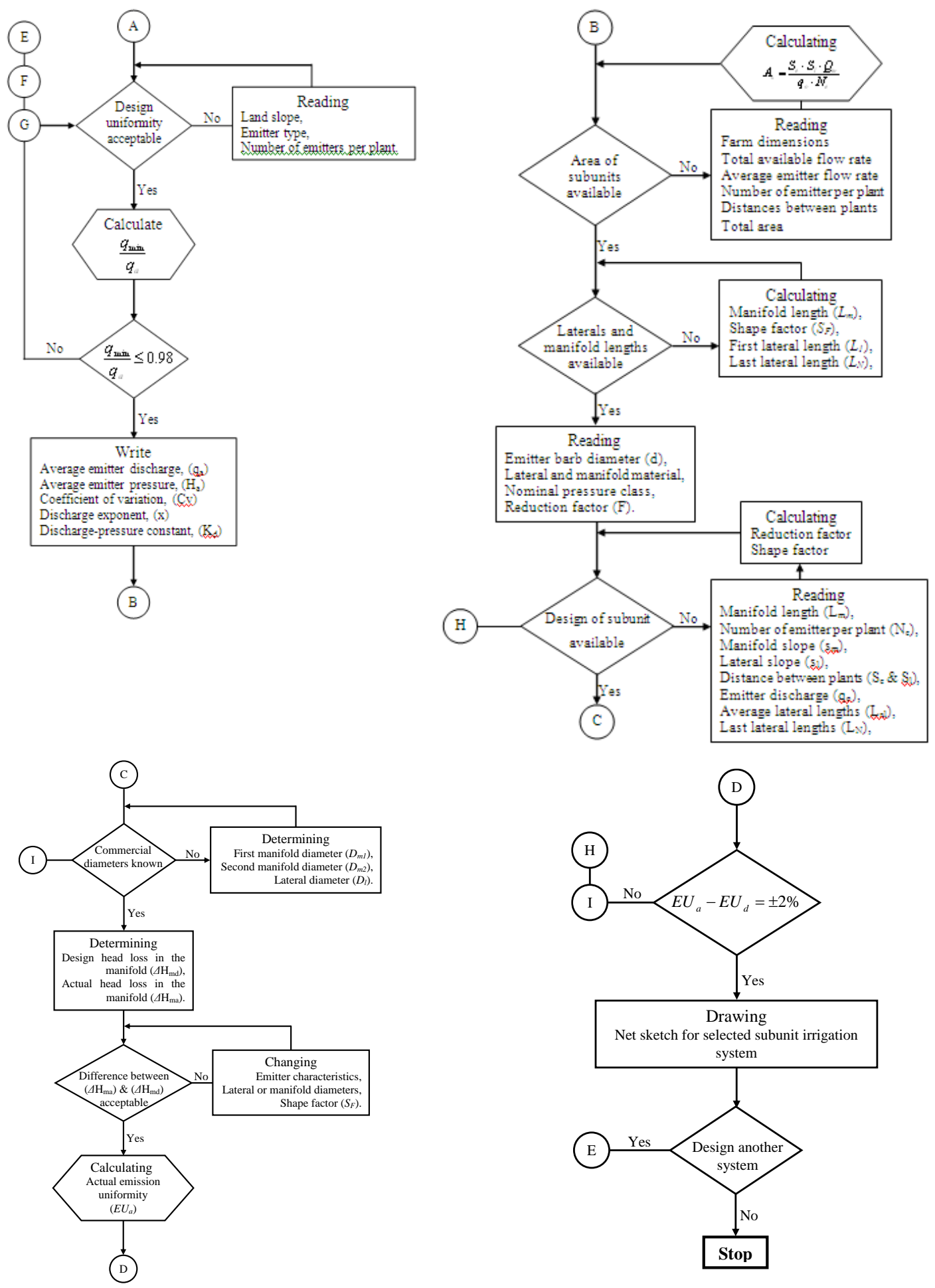

Figure [1]: Flow map of the main program of odd-shaped subunit design.

Misr J. Ag. Eng., October 2008 


\section{Emitter characteristics assessment}

The model deals with the assessment of the emitter characteristics as shown in figure [2] [discharge $\left(q_{o}\right)$, working pressure $\left(H_{o}\right)$, exponent in the pressure/flow-rate relationship $(x)$ and manufacturer coefficient of variation $\left.\left(C_{v}\right)\right]$ and the design emission uniformity coefficient $(E U)$. The model offers two possibilities to the designer; the designer can input all the parameters, otherwise accept the automatic choice proposed by the database (fig. 3).

\section{The number of emitters per plant $\left(N_{e}\right)$}

The designer has two possibilities to determine the number of emitters per plant $\left(N_{e}\right)$ : the designer can input this value (fig. 3), otherwise accept the program automatic choice answering some questions about soil and crop type, distance between plants $\left(S_{e} \& S_{l}\right)$ and type of emitter.

\section{Design emission uniformity $\left(E U_{d}\right)$}

The designer has two possibilities to choose the design emission uniformity. The designer inputs a value (fig. 1), which according to general recommendations should not be less than $85 \%$. The program chooses the $E U_{d}$ value using the rules shown in table [1] which related to the emitter spacing, the distances between the plants and the slopes (fig. 4).

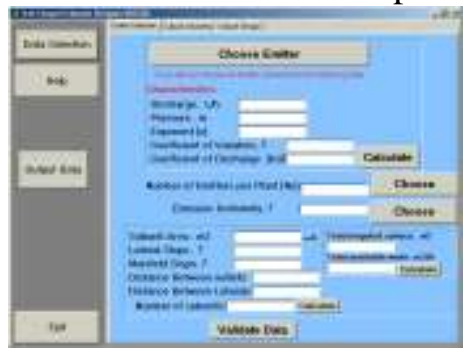

Figure [2]: The main program interface the Odd-Shaped Subunits

Designer.
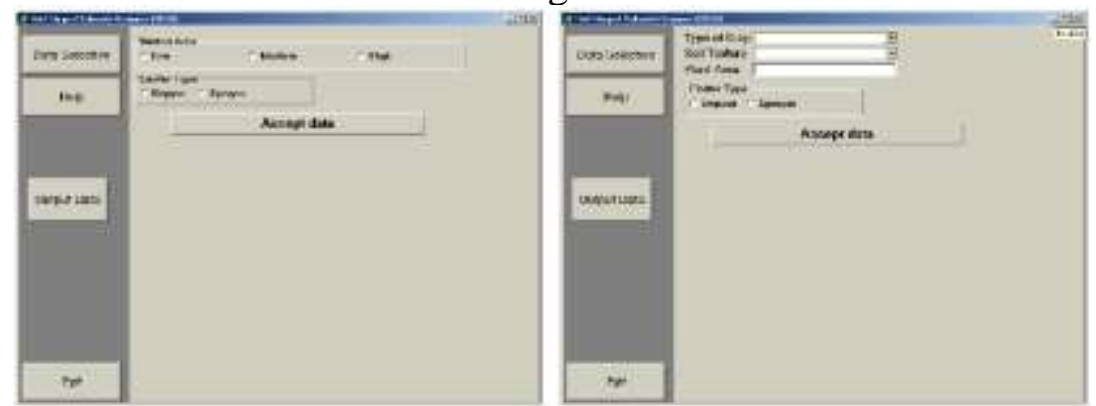

Figure [3]: Interface for choose emitter. Figure [4]: Interface for selected number of emitters per plant proposed by the program 


\section{Number and subunit area}

The designer can simply input this data in the model (fig. 1); otherwise determine the area of subunits. The input data are total discharge, single plant area, total area, number of emitters per plant, average emitter discharge.

$$
A_{s}=\frac{S_{e} \cdot S_{l} \cdot Q_{m}}{q_{a} \cdot N_{e}}
$$

In which; $Q_{m}$ is the flow rate at inlet of the manifold and $A_{s}$ is the subunit area. Before closing this module the program evaluates the value of emission uniformity, which should not be lower than 0.90; if this value lower than preset limit, the program will warning and help the user to change $E U_{d}$.

\section{Allowable pressure head variation in subunit $\left(\Delta H_{s}\right)_{a}$}

The allowed variation in pressure within a subunit depends on; the allowed variation in discharge $\left(q_{v a r}\right)$ and the emitter exponent $(x)$. The allowed variation in discharge describes the potential variation that can occur expressed as the ratio of the minimum discharge to the average discharge. Minimum emitter discharge that will satisfy the desired emission uniformity value can be determined by solving the uniformity equation by using the average discharge and $C_{v}$ for the selected emitter.

$$
\left(\Delta H_{s}\right)_{a}=1-\left(1-q_{\mathrm{var}}\right)^{\frac{1}{x}}
$$

Accordingly, $\left(\Delta H_{s}\right)_{a}$ can be around $20 \%$ in emitters with a turbulent flow $(\mathrm{x}=0.45$ to 0.55$)$. Of course $\left(\Delta H_{s}\right)_{a}$ in subunit that will give $\mathrm{EU}$ reasonably close to assumed design value can be computed for design purposes from equation [4].

$$
\left(\Delta H_{s}\right)_{a}=0.2 H_{o}
$$

Table [1]: Rules for choosing design emission uniformity for different source types and slopes. [Modified from Keller and Karmeli 1975].

\begin{tabular}{|l|c|c|c|}
\hline Emitter type & Emitters per plants & Slope, \% & $\boldsymbol{E U}_{\boldsymbol{d}}, \boldsymbol{\%}$ \\
\hline Point Source & $\geq 3$ & $\leq 2$ & 92.5 \\
\hline Point Source & $<3$ & $\leq 2$ & 87.5 \\
\hline Point Source & $\geq 3$ & $>2$ & 87.5 \\
\hline Point Source & $<3$ & $>2$ & 85 \\
\hline Spray & All & $\leq 2$ & 92.5 \\
\hline Spray & All & $>2$ & 87.5 \\
\hline Line Source & All & $\leq 2$ & 85 \\
\hline Line Source & All & $>2$ & 77.5 \\
\hline
\end{tabular}




\section{Shape factor assessment $\left(S_{F}\right)$}

Shape factor value ranged from 0 to 2 as discussed before and depends on the lateral and manifold slopes. The shape factor for the manifold is defined as:

$$
S_{F}=\frac{2}{1+\left(L_{1} / L_{N}\right)}
$$

\section{Laterals and manifold lengths}

The objective of this step is to calculate the manifold and the average lateral lengths. The designer has to determine the manifold and lateral lengths as shown in figure [5] or accept the program automatically choice by pressing calculate. The common workable single lateral lengths are from $40 \mathrm{~m}$ to $100 \mathrm{~m}$ and the common workable single manifold lengths are from 100 to $200 \mathrm{~m}$ (El-Nesr et al., 2001). Based on the workable, laterals and manifolds lengths and the number of operating stations $\left(N_{s}\right)$, the range of acceptable subunit areas $\left(A_{s}\right)$ could be obtained. Considering each value of acceptable subunit areas. After selecting the economical manifold length and spacing, the next step is to layout the system. For leveling farms and/or single lateral and manifolds, the subunit dimension and total number of subunits could be determined.

\section{Diameters of the pipe network}

The objective of this step is to calculate the diameters $\left(D_{m} \& D_{l}\right)$ of the pipe network, which permits to limit the variation between the selected and the final emission uniformity coefficient within the selected limits. This step is complex because it is necessary to determine the diameters of the pipes and it is possible that some data entered previously should be changed if the results are not consistent. To design the pipe network some data about them are needed; number of outlets in the laterals, number of emitters per plant on the lateral, distance between outlets on the lateral, distance between laterals on the manifold, lateral and manifold lengths and, lateral and manifold slope, the designer has two possibilities; the user inputs the values (fig. 6); otherwise the program chooses the values using the following rules: 


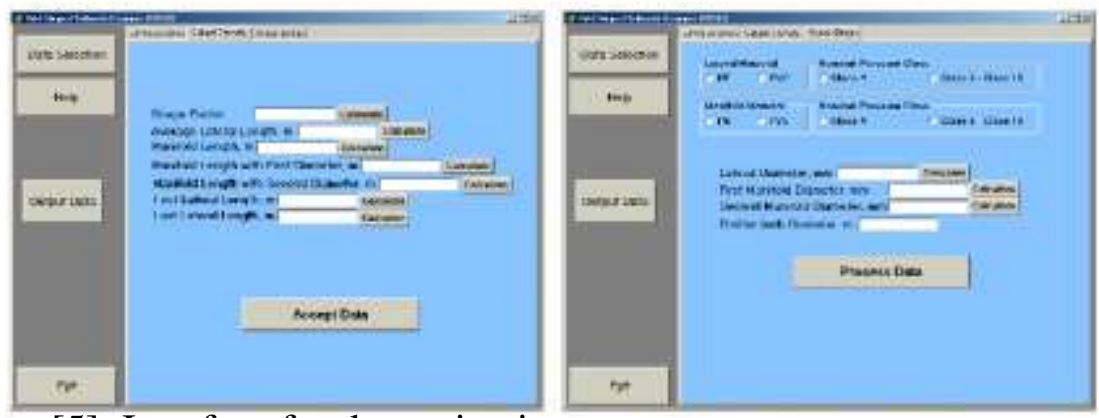

Figure [5]: Interface for determination Figure [6]: Interface for determination of manifold and laterals lengths

10. proposed by the program 10. Trickle lateral design

of manifold and laterals diameters

proposed by the program.

The lateral design procedures for all trickle systems are essentially the same. As a general guideline for sizing the average lateral $\left[L_{a}\right.$ or (average length of pair lateral) $\left.L_{a p} / 2.0\right],\left(\Delta H_{s}\right)_{a}$ can be allocated equally between the lateral and manifold; (i.e., $\Delta H_{l}=H_{\text {leq }}=0.50-0.55 \Delta H_{s}$ and $\Delta H_{m}=$ $0.45-0.5 \Delta H_{s}$ ) (Benami and Ofen, 1983). The lateral outside diameter should be assumed within the available sizes, $(12,14,16,18$ and 20 $\mathrm{mm})$. Then, calculate the friction loss in the lateral $\left(H_{\text {leq }}\right)$ and it compared with allowable $\left[\Delta H_{s}\right]$. The selected size is considered satisfactory if the actual head loss is less or equals the allowable. The hydraulic design is based on single or pair of laterals having the average discharge in each subunit. Hydraulic design includes determining best lateral diameter and pressure variation along the last lateral. This can be done for constant diameter lateral on uniform slope by using either graphical or numerical methods (Keller and Rodrigo 1979). Numerical method is used herein because of its simplicity for programming. The ground slope must be fairly uniform, so it can be represented by a straight line, for numerical procedures to apply.

\section{[I] Single lateral}

Single lateral design includes the following procedure:

1. Compute the lateral diameter $\left(D_{l}\right)$ according to discharge equation with velocity should be limited to be about $1.5 \mathrm{~m} / \mathrm{s}$ from equation (6):

$$
D_{l}=\left(\frac{0.24 L_{a l} \cdot q_{e} \cdot N_{e}}{S_{e}}\right)^{0.5}
$$

2. Assess the reduction factor value $(F)$. 
3. Compute the equivalent head loss of the lateral with emitters from equation [7]:

$$
H_{\text {leq }}=K \cdot F \cdot \frac{\left[q_{o} \cdot N_{e}\right]^{1.75}}{D_{l}^{4.75}} \cdot n_{l}^{2.75} \cdot\left[S_{e}+f_{e}\right]
$$

4. Compute the lateral pressure head variation $\left(\Delta H_{l}\right)$ from equation [8]:

$$
\Delta H_{l}=\left(K \cdot F \cdot \frac{\left[q_{o} \cdot N_{e}\right]^{1.75}}{D_{l}^{4.75}} \cdot n_{l}^{2.75} \cdot\left[S_{e}+f_{e}\right]\right) \pm\left(s_{l} \cdot\left[\frac{L_{N}}{100}\right]\right)
$$

\section{[II] Pairs of laterals}

Pair's lateral design includes the following procedure:

1. Compute the lateral diameter $\left(D_{l}\right)$ according to discharge equation with velocity should be limited to be about $1.5 \mathrm{~m} / \mathrm{s}$ from equation (6).

2. Compute the friction head loss for a single lateral with a total length and flow rate equal to that of the pair of laterals $\left(H_{\text {leqp }}\right)$ from equation [7].

3. Calculate the absolute difference in elevation between the outer ends of the pair of laterals $\left(\Delta S_{l p}\right)$ from equation [9]:

$$
\Delta S_{l p}=\frac{L_{p} \times \text { Lateralslope }}{100}
$$

4. Compute the lateral pressure head variation $\left(\Delta H_{l}\right)$ from equation [8]:

\section{Trickle manifold design}

The manifold outside diameter should be assumed within the available sizes, $(50,63,75,90$ and $110 \mathrm{~mm})$. Then, calculate the friction loss in the manifold $\left(H_{m}\right)$ and it compared with allowable $\left[\Delta H_{s}\right]$. The selected size is considered satisfactory if the actual head loss is less or equals the allowable. The hydraulic design is based on single or pair of manifolds.

Selecting pipe sizes for tapered manifolds involves two criteria:

1. Balance between friction loss, elevation change, and allowable pressure variation.

2. Permissible velocity (controls minimum pipe sizes regardless of other criteria).

\section{[I] Single manifold}

1. Determine the each manifold branch length from equations [10] and [11].

$$
\begin{aligned}
& L_{m 1}=0.5 L_{m} \\
& L_{m 2}=0.5 L_{m}
\end{aligned}
$$

2. Compute the manifold diameters for each branch $\left(D_{m 1} \& D_{m 2}\right)$ according to the discharge equation with velocity should be limited to 
be about $2 \mathrm{~m} / \mathrm{s}$ from equations (12) and (13). For all selected segment sizes, the sequence and velocity limitation must be checked.

$$
\begin{gathered}
D_{m 1}=\left(\frac{0.18 L_{a l} \cdot q_{o} \cdot N_{e} \cdot L_{m}}{S_{e} \cdot S_{l}}\right)^{0.5} \\
D_{m 2}=\left(\frac{0.09 L_{m 2} \cdot q_{o} \cdot N_{e} \cdot\left(L_{a l}+L_{N}\right)}{S_{e} \cdot S_{l}}\right)^{0.5}
\end{gathered}
$$

3. Assess the modified reduction factor value $(F)$ from the mathematical analysis [Eq. 5].

4. Compute the head losses of the manifold $\left(H_{m}\right)$ from equation [14].

$$
H_{m}=\left[\frac{F \cdot K\left(N_{l} \cdot N_{e} \cdot q_{o}\right)^{1.75}}{S_{e}^{1.75} \cdot D_{m}^{4.75}}\right]\left[L_{a l}^{1.75} \cdot L_{m}+a \cdot L_{m 2}\left(L_{a l}+L_{N}\right)\left(1+\frac{D_{m}^{4.75}}{D_{m 2}^{4.75}}\right)\right]
$$

5. Compute the manifold pressure head variation $\left(\Delta H_{m}\right)$ from equation [15]:

$$
\Delta H_{m}=\left[\frac{F \cdot K\left(N_{l} \cdot N_{e} \cdot q_{o}\right)^{1.75}}{S_{e}^{1.75} \cdot D_{m}^{475}}\right]\left[L_{a l}^{175} \cdot L_{m}+a \cdot L_{m 2}\left(L_{a l}+L_{N}\right)\left(1+\frac{D_{m}^{4.75}}{D_{m 2}^{475}}\right)\right] \pm\left(s_{m} \cdot \frac{L_{m}}{100}\right)
$$

6. The allowable manifold pressure head variation, $\left(\Delta H_{m}\right)_{a}$ is usually equal to:

$$
\left(\Delta H_{m}\right)_{a}=\Delta H_{s}-\Delta H_{l}
$$

- If $\Delta H_{m} \leq 1.1\left(\Delta H_{m}\right)_{a}$, the design is satisfactory.

- If $\Delta H_{m}>1.1\left(\Delta H_{m}\right)_{a}$, the manifold sizes should be adjusted to reduce $H_{m}$.

Usually small adjustment can be made by inspection. For large adjustments calculate a manifold flow rate $Q_{m}$ ' for redesign by using $H_{m}$ computed in step [4]. Then, repeat steps 1 through 6 beginning with, $Q_{m}{ }^{\prime}$, until $\left(\Delta H_{m}\right)_{a}$ has been satisfied.

\section{[II] Pair's manifold}

The design strategy for pairs of manifolds is treating with two manifold sections (uphill and downhill) separately. Manifold design determines the flow rate and pipe sizes needed to give the desired average emitter discharge $\left(q_{a}\right)$ and average emitter pressure $\left(H_{a}\right)$.

Pair's manifold design includes the following procedure:

1. Calculate the absolute difference in elevation between the outer ends of the pair of manifolds $\left(\Delta S_{m p}\right)$ from equation [17]:

$$
\Delta S_{m p}=\frac{S_{m} \cdot L_{m p}}{100}
$$

2. Determine the each manifold branch length for each uphill and downhill manifold from equations [10] and [11]. 
3. Compute the manifold branches diameter $\left(D_{m 1}\right.$ and $\left.D_{m 2}\right)$ according to discharge equation with velocity should be limited to be about $2 \mathrm{~m} / \mathrm{s}$ from equation [12] and [13].

4. Compute the friction head loss for a single manifold with a total length and flow rate equal to that of the pair of manifolds $\left(H_{m p}\right)$ from equation [14].

5. Compute the manifold pressure head variation $\left(\Delta H_{m}\right)$ from equation [15].

6. Compute the allowable manifold pressure head variation, $\left(\Delta H_{m}\right)_{a}$ from equation [16]

- If $\Delta H_{m} \leq 1.1\left(\Delta H_{m}\right)_{a}$, the design is satisfactory.

- If $\Delta H_{m}>1.1\left(\Delta H_{m}\right)_{a}$, the manifold sizes should be adjusted to reduce $H_{m}$. Then, repeat steps 1 through 6 beginning with, $Q_{m}{ }^{\prime}$, until $\left(\Delta H_{m}\right)_{a}$ has been satisfied.

\section{Emission uniformity determination and evaluation}

Once the drip system has been designed, its actual emission uniformity $\left(E U_{s}\right)$ should be estimated. The trial design is acceptable since $E U_{s}$ is within $\pm 2 \%$ of the assumed $(E U)$; otherwise the program will warn and help the user to changing some factors as discussed later.

\section{RESULTS AND DISCUSSION}

The purpose of this research is to develop a computer model to make a detailed design for the pre-selected subunit shape and configurations to make the comparisons and final selection.

\section{Basic data}

Total land area $\left(\mathrm{A}_{\mathrm{t}}\right)=50000 \mathrm{~m}^{2}$, Land slope $=0 \%$, Type of crop $=$ citrus, Planting spacing $=5 \times 5 \mathrm{~m}$ and Type of soil $=$ sandy

\section{Emitter characteristics assessment}

If the user presses Data selection, the program will transfer to emitter selection interface [fig. 1], these data presented in emitter characteristics. If the user presses Choose Emitter, the program will ask the user the type of emitter; drippers or sprayers and the discharge range. If the user inputs the medium wetting area and dripper, the program will automatically search according to these data in its database and the output will be (fig. 2): $q_{a}=4 \mathrm{~L} / \mathrm{h}, H_{o}=10 \mathrm{~m}, x=0.5, C_{V}=3 \%$ and 
coefficient of discharge $=0.18$. The program will then go back again to the interface of emitter characteristics input to input number of emitters per plant and emission uniformity data.

The next step is to select the minimum number of emitters per plant otherwise the user will press Choose to go to interface for choosing the minimum number of emitters per plant (fig. 2), which requires the user to define the type of soil, type of crop, plant area and the type of emitter. Let's assume that type of soil is coarse, type of plant is citrus, type of emitter is dripper and the distances between plants are $(5 \mathrm{~m} \times 5 \mathrm{~m})$. If the user inputs that data, the program will automatically search in its database and the program will supply $N_{e}$ as 4 drippers.

The next step in the first module is to choose the emission uniformity; the user will press Choose to go to the interface of emission uniformity, which asks the user the type of emitter, slope and the range area of each plant (fig. 3). If the user inputs the slope is less than $2 \%$, the dripper is point-source and $N_{e}$ as estimated before is 4, the program will automatically search according to these data in its database and the program will supply the $E U_{d}$ as $90 \%$.

The last step in the first module is to input or choose the subunit area and number of subunits; the user will fill the total irrigated area $\left(50000 \mathrm{~m}^{2}\right)$, total available water $\left(50 \mathrm{~m}^{3} / \mathrm{h}\right)$, lateral and manifold slopes $(0 \%)$ and distances between outlets and laterals $(5 \times 5 \mathrm{~m})$ (fig. 7). The user will press calculate to permit the automatically calculation according to these data and the program will supply the subunit area as $33750 \mathrm{~m}^{2}$ and the number of subunits as 2 subunits (fig. 7). Before closing this module the program evaluates the value of emission uniformity, which should not be lower than 0.90; if this value lower than preset limit, the program will warning and help the user to change design emission uniformity, but with the previous data, the program found that this value is higher than the preset limit and it is satisfactorily.

Then the user will press Geometry of the subunit to start with the second module, dealing with manifold and lateral lengths and shape factor. 


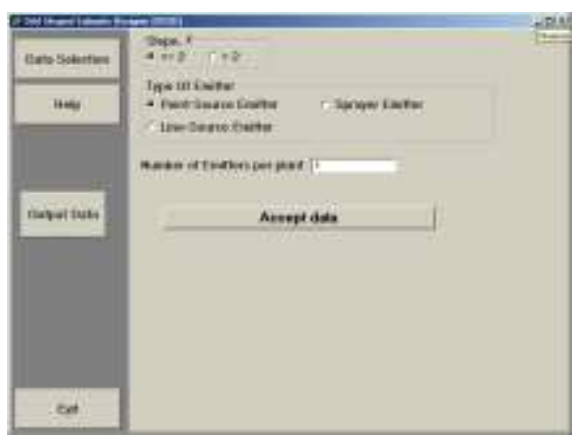

Figure [7]: Interface for selected design emission uniformity proposed by the program.

\section{Manifold and laterals lengths assessment}

The program will supply the manifold length as $110 \mathrm{~m}$, the average lateral length as $109 \mathrm{~m}$, first and second manifold lengths as 55 and $55 \mathrm{~m}$ and the first and last lateral lengths as 164 and $54 \mathrm{~m}$ respectively (fig. 5).

\section{Manifold and lateral diameters assessment}

The user inputs the values; otherwise the program chooses the values using the rules which related to the entered previous data, materials and nominal pressures. The program suggests the following data; $D_{l}$ is 18 $\mathrm{mm}, \mathrm{D}_{\mathrm{m}}$ is $110 \mathrm{~mm}$, manifold with first diameter is $63 \mathrm{~m}$ and manifold with second diameter is $32 \mathrm{~m}$.

\section{Program predicting for emission uniformity and evaluation}

The program controls the calculated emission uniformities by comparing the programmed $E U_{d}$ and $E U_{a}$ : the variation between them should not exceed $\pm 2 \%$.

\section{Program drawing for the programmed odd-shaped subunit}

After the suitable odd-shaped subunit has been selected and designed, the project should be presented by preparing plan for proper layout (fig. 8). This net sketch shows; Manifold length, Manifold length with first diameter, Manifold length with second diameter, First lateral length, Last lateral length and Manifold position.

As final, the designer has to press output data to show the last design information had been calculated (fig. 9). 


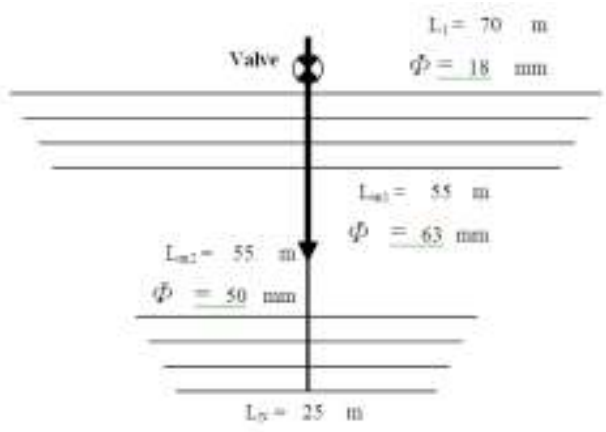

Figure [8]: Suggested programmed sketch for the odd-shaped subunit.

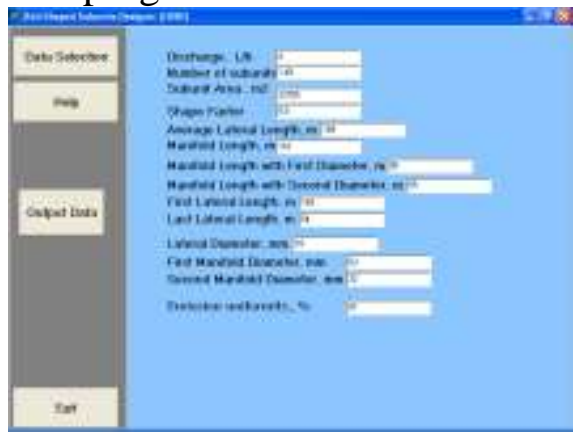

Figure [9]: Interface of final output data for the odd-shaped subunit.

\section{CONCLUSION}

Computer program was made to facilitate the designing and determining the emission uniformity of the odd-shaped subunits. It is written using Delphi language (Object Pascal Language) version 6.0 and the output windows executable file.

The model consists of the following steps:

1. Emitter selection

2. Determining the sufficient number of emitters per plant

3. Determining the design emission uniformity

4. Determining the allowable pressure head in the subunit $\left(\Delta H_{s}\right)_{a}$

5. Determining the shape factor

6. Determining the subunit area

7. Determining the manifold and laterals lengths

8. Determining the manifold and lateral diameters

9. Comparison between design emission uniformity $\left(E U_{d}\right)$ and actual emission uniformity $\left(E U_{a}\right)$

10. Drawing the designing irrigation subunit 


\section{REFERENCES}

Abdel-Wahed, M. H. 2002. Applying computer techniques for the determination of some crop water requirements and irrigation scheduling in designing drip irrigation system. Ph.D. Thesis. Ag. Eng. Dept., Fac. of Ag., Cairo Univ.

Awady, M. N. and O. M. Ahmed. 1996. Planning trickle irrigation systems by computer aid. $4^{\text {th }}$ Conference of MSAE 13 (4): $87-104$.

Bralts, V. F. and L. J. Segerlind. 1985. Finite element analysis of drip irrigation submain units. Transaction of ASAE. 28(3): 809 - 814.

Bralts, V. F., Kelly, S. F., Shayya, W. H. and L. J. Segerlind. 1993. Finite element analysis of Microirrigation hydraulics using virtual emitter system. Transaction of ASAE. 36(3): 717 - 725.

Gomes, H. P. 1996. A software for optimum design of trickle irrigation pipeline systems, $6^{\text {th }}$ Inter. Conf. on computer in Ag., Mexico.

Ismail, S. M., E. R. El-Ashry, G. A. Sharaf., and M. N. El-Nesr. 2001. Computer aided design of trickle irrigation system. Misr J. Ag. Eng., 18(2): $243-260$.

Kang, Y. and S. Nishiyama. 1994. Finite element method analysis of Microirrigation system pressure distribution. Trans., Japanese Soc. Of Irrig., Drain. And Reclamation Eng., Tokyo. Japan. 169, 19 - 26.

Kang, Y. and S. Nishiyama. 1995. Hydraulic analysis of Microirrigation submain units. Transaction of ASAE, 38 (5), 1377 - 1384.

Kang, Y. and S. Nishiyama. 1996. Design of Microirrigation submain units. J. Irrig. And Drain. Engrg., ASCE, 122(2): 75 - 82.

Keller, J. and D. Karmeli. 1975. Trickle irrigation design. Rain Bird Sprinkler Manufacturing Corporation, Glendora, CA, 133p.

Keller, J. and J. Rodrigo. 1979. Trickle irrigation lateral design. ASAE Technical Paper No. 79 - 2570.

Keller, J. and R.D. Bliesner. 1990. Sprinkler and Trickle irrigation. Published by Van Nostrant Reinhold, New York 10003.

Mahrous, A., M. Hanafy., A. S. Bazaraa. And G. A. Gomaa. 2004. Mathematical model for predicting emission uniformity of ODDshaped subunits in drip irrigation system. Modern Technology in Agric. Researches and Application. The $12^{\text {th }}$ Conference of Misr Society of Agr. Eng., 4-5 October 2004: 222-238. 
Reddy, K. Y., Tiwari. K. N. and V. Ravindra. 2000. Hydraulic analysis of trickle irrigation system for economic design. Inter. Ag. Eng. J.9(2):81-95.

Sharaf, G. A. 1991. Models for design and evaluation of drip irrigation systems. PhD. Dissertation, Dept. of Water Management and Land Reclamation, Ag. Uni. Godollo, Hungary.

Sharaf, G. A. 1996. Optimal design of trickle irrigation submain unit. Misr J. Ag. Eng., 13(3): 501 - 515.

Sharaf, G. A. 2004. A study of water distribution uniformity of microirrigation subunit. Misr J. Ag. Eng., 21(1): 103 - 124.

Sosa, G. M. 1996. Program of design of water distribution network using low pressure pipelines. $6^{\text {th }}$ Inter. Conf. on computer in Ag., Mexico.

Wu, I. P. and H. M. Gitlin. 1975. Energy gradient line for drip irrigation laterals. J. Irrig. and Drainage Div. of the ASCE 101(IR4): 323 - 326.

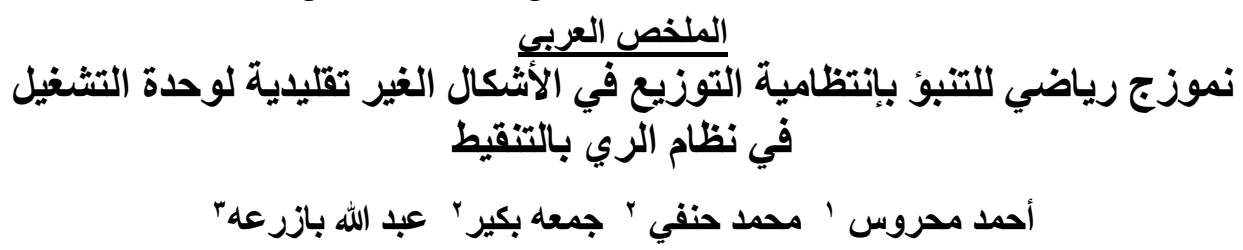

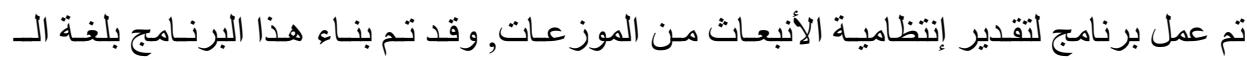
Delphi وقد أشتمل هذا البرنامج على الخطوات التالية التية:

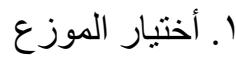

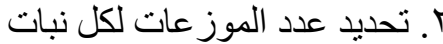
r. تقدير إنتظامية الإنبعاث من الموز عات التات التصميمية

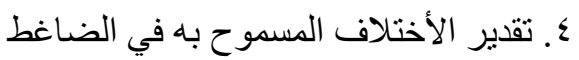
0. - تقدير معامل الثكل

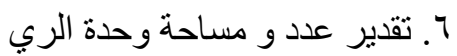
V. تقدير أطو ال خط التوزيع وخط التغذية وخدة الرية 1. تقدير قطري خط التوزيع وخط التغذية التخاية

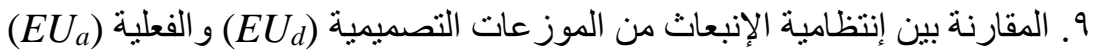

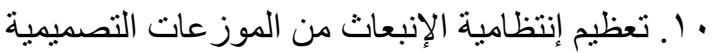

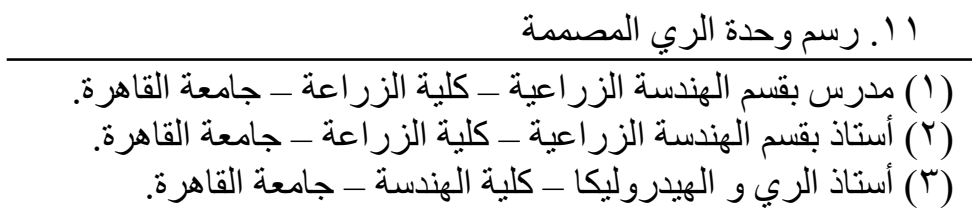

